\section{My Summer Vacation}

$\mathbf{B}^{\prime}$ $y$ the time you read this, summer will be a distant memory. Fall colors will be glowing across the country, and we will all be thinking about how and with whom to spend the winter holidays. But as I write this, I am reflecting on my short vacation at the end of August and wondering what I did wrong.

I suspect we all approach our vacations the same way. After planning the vacation and scheduling time away from the office and clinic, we must get ready to actually be away. For most of us, this means finding people to cover patients, administrative duties, and any other responsibilities. Then we work to get caught up on paperwork and other looming deadlines so that we can leave with a clear conscience. By the time we leave, we're exhausted!

We arrive at our destination drained and need to rest up. But that's OK, isn't it? After all, isn't that what a vacation is for? But wait! You also wanted to hike or bike or visit friends or do any of a million things you never get to do during a regular work week. Ok, maybe you can fit these things in later in the week. After all, a week is a nice chunk of time for a vacation, right?

Meanwhile, you've told your colleagues that you are going on vacation and you've carefully put a vacation message on your email. Anyone who knows you well would surely text or call if they really needed you. So, you promise yourself that you will NOT look at your email. But after over 500 unread messages pile up, you give in-just to "clean it up," and of course, to flag important emails to follow up on later. . . after vacation. But then you notice that your biggest program benefactor needs some advice, several patients have been hospitalized, and a colleague has a time-sensitive issue. So, you follow up. Then you follow up again. And again.

Before you know it, it is time to head home. When you get there, all the other work you should have done during the week will be waiting for you. And the cycle starts again.

As oncologists, we have intense and emotional jobs. Burnout is common. But getting the right balance of free and unencumbered time is tough. The pace of activities in our world doesn't stop when we need a break, and rapid turnaround in communication is expected these days. And I don't think that's going to change.

I'm not sure what the right answer is. I have a colleague who goes on vacation for a month each year and his out-of-office message is simple: "I'm on vacation. Email me again when I get back." Although I think that might be a bit extreme, I'll bet he's pretty rested when he returns!

As for me, I'm going to stop kidding myself that a week is enough time to recharge. If any of you have figured out how to do this right, let me know. And in case you are wondering, the week wasn't a total loss. I took golf lessons. Now I just need to find time to play. JNCCN@nccn.org or log into www.editorialmanager.com/JNCCN.

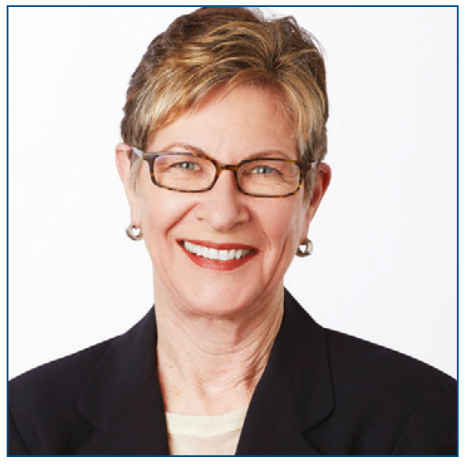

MARGARET TEMPERO, MD

Margaret Tempero, MD, is a Professor of Medicine and Director of the UCSF Pancreas Center and editor-in-chief of JNCCN. Her research career has focused on pancreatic ductal adenocarcinoma, especially in the area of investigational therapeutics. Dr. Tempero has served on the ASCO Board of Directors and as ASCO President. She currently serves on the ASCO Conquer Cancer Foundation Board. She codirected the AACR/ASCO Methods in Clinical Cancer Research and taught this course and similar courses in Europe and Australia. She was founding Chair of the $\mathrm{NCl}$ Clinical Oncology Study Section and served as a member and Chair of the $\mathrm{NCl}$ Board of Scientific Counselors Subcommittee A. She is a member of the Scientific Steering Committee and Chair of the Clinical and Translational Study Section for the Cancer Prevention \& Research Institute of Texas. She is or has been on the Scientific Advisory Boards of the Lustgarten Foundation, the Pancreatic Cancer Action Network, the V Foundation, The Alberta Canada Cancer Board, and the EORTC. She served as a member of the Oncology Drug Advisory Committee for the FDA. She has served as Deputy Director and Interim Director for the UNMC Eppley Cancer Center. She is Chief Emeritus of the Division of Medical Oncology at UCSF. She served as the founding Deputy Director and was later Director of Research Programs at the UCSF Helen Diller Family Comprehensive Cancer Center.

doi: $10.6004 /$ jnccn.2019.0050

The ideas and viewpoints expressed in this editorial are those of the author and do not necessarily represent any policy, position, or program of NCCN. 